(C) 2021, The Authors. Published by Elsevier Inc. and Fass Inc. on behalf of the American Dairy Science Association ${ }^{\circledR}$. This is an open access article under the CC BY-NC-ND license (http://creativecommons.org/licenses/by-nc-nd/4.0/).

\title{
Feasibility of the use of deep learning classification of teat-end condition in Holstein cattle
}

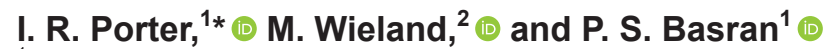 \\ ${ }^{1}$ Department of Clinical Sciences, College of Veterinary Medicine, Cornell University, Ithaca, NY 14853 \\ ${ }^{2}$ Department of Population Medicine and Diagnostic Sciences, College of Veterinary Medicine, Cornell University, Ithaca, NY 14853
}

\section{ABSTRACT}

Infections with pathogenic bacteria entering the mammary gland through the teat canal are the most common cause of mastitis in dairy cows; therefore, sustaining the integrity of the teat canal and its adjacent tissues is critical to resist infection. The ability to monitor teat tissue condition is a key prerequisite for udder health management in dairy cows. However, to date, routine assessment of teat condition is limited to cow-side visual inspection, making the evaluation a time-consuming and expensive process. Here, we demonstrate a digital teat-end condition assessment by way of deep learning. A total of 398 digital images from dairy cows' udders were collected on 2 commercial farms using a digital camera. The degree of teat-end hyperkeratosis was scored using a 4-point scale. A deep learning network from a transfer learning approach (GoogLeNet; Google Inc., Mountain View, CA) was developed to predict the teat-end condition from the digital images. Teat-end images were split into training (70\%) and validation (15\%) data sets to develop the network, and then evaluated on the remaining test $(15 \%)$ data set. The areas under the receiver operator characteristic curves on the test data set for classification scores of normal, smooth, rough, and very rough were $0.778(0.716-0.833), 0.542(0.459-0.608), 0.863$ (0.788-0.906), and 0.920 (0.803-0.986), respectively. We found that image-based teat-end scoring by way of deep learning is possible and, coupled with improvements in image acquisition and processing, this method can be used to assess teat-end condition in a systematic and efficient manner.

Key words: teat-end condition, hyperkeratosis, mastitis, digital imaging, bovine

Received September 14, 2020.

Accepted November 16, 2020.

*Corresponding author: irp5@cornell.edu

\section{INTRODUCTION}

Mastitis is one of the most frequently occurring diseases of dairy cows. It has well-recognized negative effects on animal welfare and on the profitability of the dairy industry (Ruegg, 2017). A 2017 study estimated the average cost per clinical case of mastitis in the United States to be US\$325 (Liang et al., 2017). A 2018 study estimated the cost of mastitis on a typical Canadian dairy farm to be approximately US $\$ 500$ per milking cow per year. In this study, $48 \%$ of the cost was attributed to subclinical mastitis (reduced milk yield being most important), $34 \%$ was attributed to clinical mastitis, and $15 \%$ was due to preventative measures (Aghamohammadi et al., 2018). In addition to cost, increased use of antibiotics may lead to increased risks of bulk tank antibiotic residue violations and poses concerns for development of antibiotic resistance that could result in the transfer of antibiotic-resistant bacteria to the food supply (Oliver et al., 2011).

The majority of mastitis cases are caused by intramammary infection, where pathogenic bacteria enter the mammary gland through the teat canal. The teat canal is therefore considered the cow's first line of defense against mastitis pathogens (O'Shea, 1987). Sustaining teat canal integrity and pliability of its adjacent tissues is critical to resisting intramammary infection. Machine milking can have a substantial effect on the condition of the teat. Vacuum-induced forces that are applied during machine milking create stress to the teat, which can evoke mechanical and circulatory impairment of its tissue (Hamann et al., 1994). These machine milking-induced alterations are differentiated into short-term, medium-term, and long-term teat tissue changes. Long-term changes are the adaptation of the teat tissue to machine milking over several weeks or longer and result in increased teat-end callosity thickness and roughness (Neijenhuis et al., 2000). Increased teat-end callosity thickness and roughness affect teat canal closure, enhance lodging of pathogenic bacteria, and consequently increase the risk of new intramammary infection (Neijenhuis et al., 2001). Although incompletely characterized, a complicated interaction of 
many factors including milking machine [e.g., vacuum level (Hamann et al., 1993), liner type (Haeussermann et al., 2016), automatic take-off settings (Rasmussen, 1993)], milking routine [e.g., milking frequency (Gleeson et al., 2007), premilking stimulation (Wieland et al., 2020), use and type of skin conditioner of postmilking teat disinfection (Goldberg et al., 1994)], and environmental factors [e.g., temperature and humidity (Burmeister et al., 1995), type of bedding (Gleeson, 2013)] may predispose the teat end to machine milkinginduced injury and influence the incidence of longterm teat tissue changes. Early detection of long-term changes is important because once present, there may be a substantial lag time between implementation of corrective measures and resolution of teat-end callosity, potentially creating a prolonged period of increased risk for new intramammary infection. Frequent monitoring of teat-end callosity is therefore an important part of a mastitis prevention program.

A scheme has been previously described for classifying long-term teat tissue changes (Mein et al., 2001) and is used clinically through cow-side evaluation. Current industry guidelines recommend evaluating at least 80 cows, or a minimum of $20 \%$ of cows in herds larger than 400 cows (Mein et al., 2001). The time-intensive nature of this evaluation hampers the ability of dairy producers to routinely monitor teat-end condition and initiate early implementation of corrective action to degrading condition. Another limitation is the subjectiveness of the observation-based scoring system, where inter- and intrarater agreement confound the accuracy of monitoring trends in teat-end condition. There is an industry need to improve the reliability, reproducibility, and efficiency in teat-end condition assessments for dairy cows.

In a recent study (Basran et al., 2020), we found that trained observer evaluation of digital images could be an acceptable alternative to in-person cow-side evaluation of long-term teat tissue changes. This workflow includes data collection by way of digital image collection of dairy cow teat ends, image processing, and the use of a graphical user interface to facilitate image-based assessment of teat-end condition using the traditional ordinal quarter-level scoring system. A digital workflow for teat condition assessment has several advantages including the ability to quantify inter- and intrarater variability, the possibility of remote assessment of teat condition, and the opportunity to adopt big data and artificial intelligence approaches for improving cattle health.

To make a digital teat-end evaluation system an attractive and practical alternative to cow-side evaluation, a fully automated system will need to be developed that can be deployed on a commercial dairy and that acquires teat images with sufficient quality, processes the images to analyze the teat ends, automates the teat-end condition scoring, and computes a herd- or pen-level prevalence of teat-end callosity. Our research focus is on improving the efficiency and accuracy of dairy health management through automation. The purpose of this work is to demonstrate the feasibility of the use of a deep learning neural network for classification of teat-end condition in digital images.

We hypothesized that deep learning can be used to assess teat-end condition in dairy cows by means of digital imaging. We describe the data preparation and digital assessment of teat-end condition and the training of a deep learning network for automated teat-end scoring, and we demonstrate utility by evaluating the performance of the deep learning system using a test data set.

\section{MATERIALS AND METHODS}

\section{Data Preparation and Classification Schema}

A total of 398 digital images of dairy cow teats on 2 commercial New York dairy farms were obtained: farm A, milking approximately 1,600 Holstein cows in a 60-stall rotary parlor, and farm $\mathrm{B}$, milking approximately 4,000 Holstein cows in a 100-stall rotary parlor. All procedures were reviewed and approved by the Cornell University Institutional Animal Care and Use Committee (protocol no. 2013-0064). A convenience sample of lactating cattle was selected during a visit to 1 milking session at each farm and included both firstlactation and mature animals (the distribution of firstlactation vs. mature cattle was not recorded). Exclusion criteria included udder abnormalities such as nonlactating quarters or teat injuries. A total of 207 (farm A) and 191 (farm B) images were collected in the fall of 2019 and summer of 2020, respectively, using digital cameras of common smartphones (farm A: iPhone6+, Apple Inc., Cupertino, CA; farm B: Samsung Galaxy S10, Samsung Electronics, Suwon, South Korea) with a maximum resolution of $4,032 \times 3,024$ pixels. Each camera was set to use default settings, with the flash disabled. The images were acquired immediately after removal of the milking cluster, before postmilking teat disinfection was applied, in ambient light in the milking parlor environment (no supplemental lighting was used for this project). Images were taken sequentially such that only 1 image of a cow's udder on the rotary parlor was obtained. The camera was held immediately behind the rear legs and pointed such that it was aimed parallel with the long axis of the cow and upward at an approximately $45^{\circ}$ angle to acquire a single image of the udder that included all teats. The distance from 
the camera to the udder varied based on the position of the legs and conformation of the udder. With the rotary parlor in motion and the cows rotating past the photographer, the shutter release was triggered when the cow was centered in front of the camera.

Images were downloaded and processed with a commercially available software program (Matlab, version 2020a, The MathWorks Inc., Natick, MA). One investigator (PSB) visually identified individual teats from the images and subsampled the original image data by cropping and labeling (right front, left front, right hind, and left hind) an image of each teat. For each cow, both the original and subsampled images were transferred to a custom-designed graphical user interface (Basran et al., 2020). Using the graphical user interface, the 4 individual teat images of each cow were presented to a trained investigator (MW) and evaluated according to the 4-point scoring system as previously described (Mein et al., 2001): normal with no callosity ring present ( $\mathbf{N}$, or score 1), smooth callosity ring present with no or only mild roughness and no keratin fronds (S, or score 2), callosity ring present with rough isolated fronds of old keratin extending 1 to $3 \mathrm{~mm}$ from the orifice ( $\mathbf{R}$, or score 3 ), and callosity ring present with very rough fronds of old keratin extending $\geq 4 \mathrm{~mm}$ from the orifice (VR, or score 4). Additionally, pigmentation status at the distal aspect of the teat end (i.e., pigmented vs. no pigmentation) was documented, but the number of pigmented and nonpigmented images was insufficient to reliably deploy the deep learning to examine the influence of pigmentation status on classification accuracy. Images for which evaluation of the teat end was not possible (e.g., teat end is obscured by an adjacent teat, the entire teat end not included in the image) were excluded. The graphical user interface streamlined recording of the results by creating a copy of the classified image that included the evaluator ID, cow ID, and teat classification score in the image's filename.

\section{Deep Learning System and Performance Evaluation}

A deep learning system to predict teat-end scores was developed (see Figure 1). Creating a deep learning model typically requires a large (i.e., thousands of images) data set of labeled or preclassified data. This is challenging and costly to produce. The approach that we used to overcome this challenge is a technique called transfer learning. In transfer learning, a pretrained model that has been trained and validated on a large data set to identify thousands of commonly found objects (e.g., cat, ball, car) is retrained on a different, smaller data set. When the model is retrained, the final classification (originally commonly found objects) is re- placed by the teat-end classification (N, S, R, or VR). The underlying assumption is that basic image features may be shared among seemingly disparate data sets. Another technique used in this study that can further assist training and validation of a small data set is called data augmentation. With data augmentation, image variants from the training and validation data set are created. These variants are created by applying random transformations such as flipping, rotation, translation, zooming, skewing, and elastic deformation to the original data without changing the appropriateness of the label for the images' classification assignment. The result is an artificial increase in the size of the training and validation data set that can help reduce the time and cost of producing a large, labeled training and validation data set (Chartrand et al., 2017; Mikołajczyk and Grochowski, 2018).

For this work, deep learning was performed on a Matlab deep learning module using a pretrained convolution neural network (CNN; GoogLeNet, Google Inc., Mountain View, CA). The scripts used for deep learning along with sample test data are publicly available via GitHub (Basran, 2020). A detailed description of CNN for deep learning classification may be found elsewhere (Rawat and Wang, 2017). Briefly, in GoogLeNet, the CNN comprises 144 different layers where features are extracted from an image within those layers, and, through an iterative process, the network learns to recognize features that can classify the image by attributing weights within each of the 144 layers to define the object. The CNN is initially designed to attribute a probability of classification for an arbitrary $224 \times 224$ pixel image from more than 1,000 predefined classifications (e.g., cat, ball, car).

The data set was divided into $70 \%$ training, $15 \%$ validation, and $15 \%$ testing data sets. The training and validation data sets were used to develop the deep learning network. To improve the performance of the neural network, the data were augmented during each training session by randomly rotating the teat-end images by $\pm 30^{\circ}$, zooming the image by $\pm 20 \%$, reflecting the images (left-right), and shifting the centroid of the image vertically and horizontally by \pm 30 pixels. To accommodate for the imbalances in the different number of images within each class and to improve the network performance for classes with small data sets, class balancing was used where image sets are deliberately copied in minority classes (Kenta, 2020).

In the transfer learning configuration, all learnable layers were trainable, where the weights of each layer are allowed to be changed. The number epochs, which is a session where the learning algorithm is exposed to all training images, were set at 30 . During each epoch a stochastic gradient descent algorithm was used to ad- 


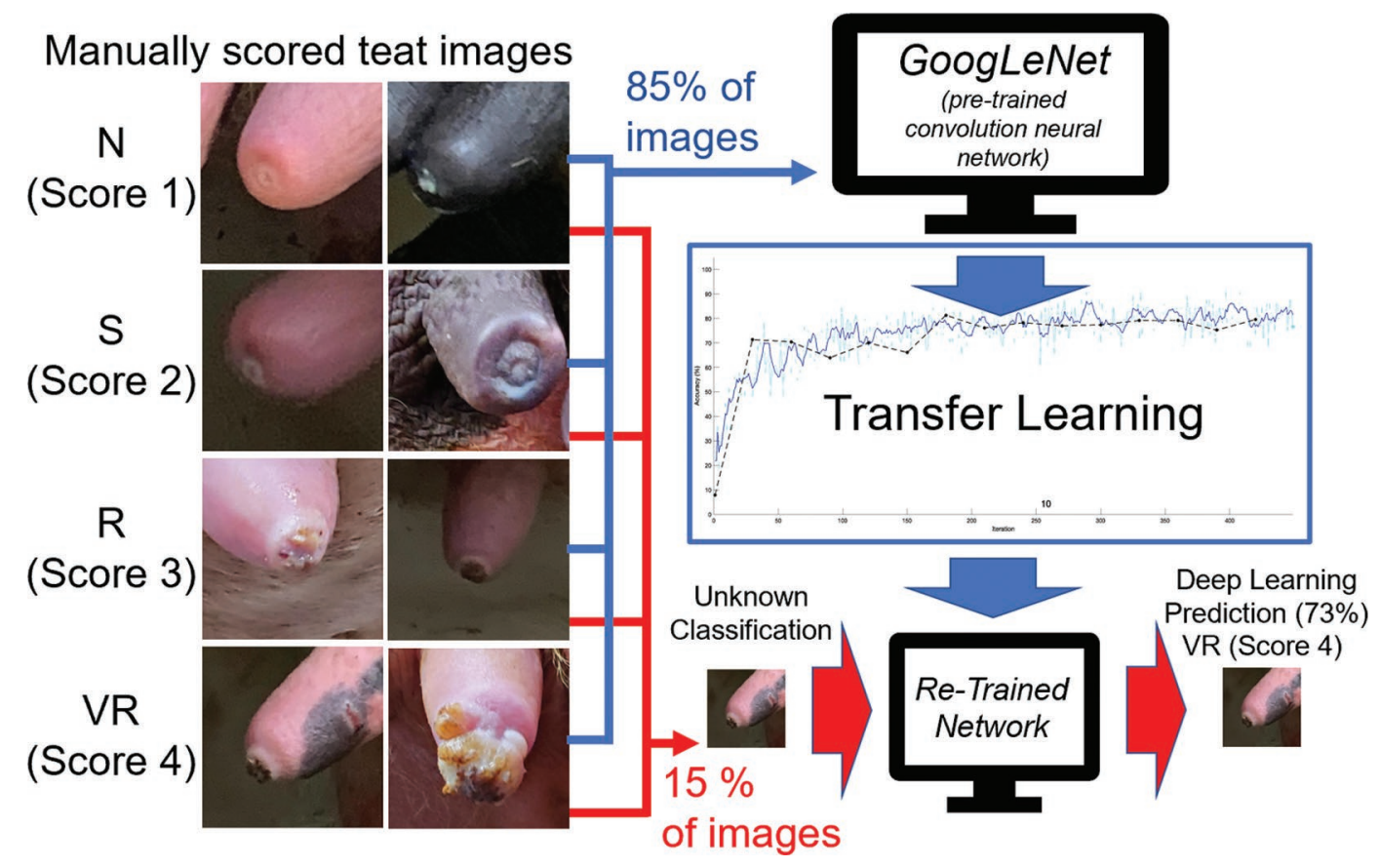

Figure 1. Workflow for deep learning teat image classification. Teat images were manually scored with a graphical user interface and stored. The classified images were then separated into training and testing data sets for transfer learning with GoogLeNet (Google Inc., Mountain View, $\mathrm{CA}$ ), and the convolution neural network was retrained. To evaluate the retrained network, independent test images were scored by the system and the prediction was compared with the manual score. Score $1(\mathrm{~N})=$ no callosity ring present; score $2(\mathrm{~S})=$ callosity ring present with no or only mild roughness and no keratin fronds; score $3(\mathrm{R})=$ callosity ring present with rough isolated fronds of old keratin extending 1 to 3 mm from the orifice; and score $4(\mathrm{VR})=$ callosity ring present with rough fronds of old keratin extending $\geq 4 \mathrm{~mm}$ from the orifice.

just the weights of each trainable layer. During training of a model, the loss (error) value is calculated to represent the error between the model's output-predicted teat-end condition score and the actual score of the input. This error is back propagated into the model to adjust weights within the model in a manner that minimizes the loss (error) by optimizing hyperparameters or weights within the model to maximize the model accuracy. Accuracy of the model is defined as the ratio of correctly predicted samples over all predictions (Chartrand et al., 2017).

A deep learning pitfall, particularly on small data sets, is a condition called overfitting. Overfitting is a modeling error that occurs when a function is too closely fit to a limited number of data points, with the model learning both the features and noise in the training data to a degree that negatively affects the performance of the model on naive (test) data. Overfitting may be detected in a model by plotting training and validation loss and controlled by smoothing weights through a process called regularization. Overfitting was monitored by inspecting the progress of the algorithm performance through a loss function and smoothing the weights through data regularization (values ranging from 0.01 to 0.0001 ). After the model was trained and validated, the final $15 \%$ of the data set was used to test the predictive model. The deep learning network provides a probability of classification of the image, which ranges from 0 to $100 \%$. The predicted score is defined as the deep learning predicted class with the highest probability.

To test our hypothesis that deep learning can be used to assess teat-end condition in dairy cows and evaluate the predictive model, we computed the receiver operator characteristic curves, including the area under the curve (AUC) for each classification category, along with $95 \%$ confidence limits. In addition, we determined the accuracy of the model, defined as the average percentage of correct predictions over all teat-end condition scores.

\section{RESULTS}

A total of 1,589 teat images (farm A, 767; farm B, 763) were available for analyses. Of these, 39 images $(2.5 \%)$ were excluded in the deep learning because they were not classifiable. Among the remaining 1,550 images, 599 (38.6\%), 654 (42.2\%), 269 (17.4\%), and $28(1.8 \%)$ were classified as score N, S, R, and VR, respectively.

The overall accuracy, or the probability an image would be scored correctly in one of the 4 classifica- 
tions, achieved at the completion of the training and validation was $77.4 \%$, and the AUC from the training and validation data sets were $0.997,0.373,0.882$, and 0.937 for scores N, S, V, and R, respectively. No overfitting (increases in the loss function) was observed in all simulations. This trained model was then used to predict the teat-end condition score on the independent test data. The test data comprised $15 \%$ of the original data set, where $88,98,37$, and 4 teat images had a score of N, S, R, and VR, respectively. Figure 2 displays the receiver operator characteristic curves for the test data set for all 4 classification categories. The AUC and their $95 \%$ confidence limits for classifications were 0.778 (0.716-0.833), 0.542 (0.459-0.608), 0.863 (0.788-0.906), and $0.920(0.803-0.986)$ for scores $\mathrm{N}$, $\mathrm{S}, \mathrm{R}$, and VR, respectively. The overall accuracy was $46.7 \%$. A perfect receiver operator characteristic curve would be a vertical line when 1 - sensitivity equal zero and a horizontal line when specificity equals 1 , whereas a random guess would be a diagonal line. The confusion or error matrix (Figure 3) displays predicted compared with the true classifications. Note that score $\mathrm{N}$ teats were mostly predicted as $\mathrm{S}$ teats, and the majority of score $\mathrm{S}$ and $\mathrm{R}$ teats were predicted correctly, whereas only 1 of the 4 score VR teats was predicted correctly. Figure 4 displays 4 teat images without contrast and brightness adjustments and their manual scores along with the corresponding deep learning score predictions and percentages.

\section{DISCUSSION}

In this feasibility study, we used a relatively small data set collected during a single visit to 2 individual farms, applied data augmentation to increase the sample size, and used transfer learning with a pretrained model to develop a new model for scoring teat-end condition in lactating Holstein cattle. Our results from the test data indicate that it is possible to use deep learning to classify teat-end condition through the use of digital images and deep learning.

The low overall accuracy in the deep learning system stems from poor prediction accuracy for score S. The deep learning system predicted teat-end condition more accurately when the true classification was $\mathrm{S}$ and R. Conversely, for the true classification VR, the deep learning system biased results toward score $\mathrm{R}$. The deep learning biasing of score $\mathrm{N}$ to $\mathrm{S}$ and score VR to R may be attributable to several factors. First, considering the subtle differences between score $\mathrm{N}$ and $\mathrm{S}$, the deep learning system would benefit from additional high-quality images in the training data. Second, in our experience, differences between scores $\mathrm{N}$ and $\mathrm{S}$ often are subtle and difficult to discriminate via visual assessment. It is therefore possible that uncertainties in evaluating scores $\mathrm{N}$ versus $\mathrm{S}$ are larger than those between other scores. This could have had an effect on training efficacy of the deep learning system. Third, it is possible that manual classification from digital images was not optimal. One advantage of $\mathrm{CNN}$ is the ability of the network to detect features within images that would otherwise be imperceptible to the human eye. For instance, the extent of hyperkeratosis in the original upper left teat image of Figure 4 is better appreciated when the contrast and brightness are adjusted and thus could lead to a different score. This highlights a potential pitfall in manual teat scoring in digital teat scoring, or an advantage in deep learning, when images suffer from poor contrast and lighting. Last, it is important to note that the number of test data with true classification of VR was very small, and thus it is likely that with more training images, the deep learning prediction would improve for both scores $\mathrm{N}$ and VR.

\section{Study Limitations}

This work has several shortcomings. First, our data set was collected at only 2 sites and at a single time point at each, where the dairy cows' teats were in relatively good condition. This resulted in imbalanced data, favoring healthier (scores $\mathrm{N}$ and $\mathrm{S}$ ) teat-end condition.

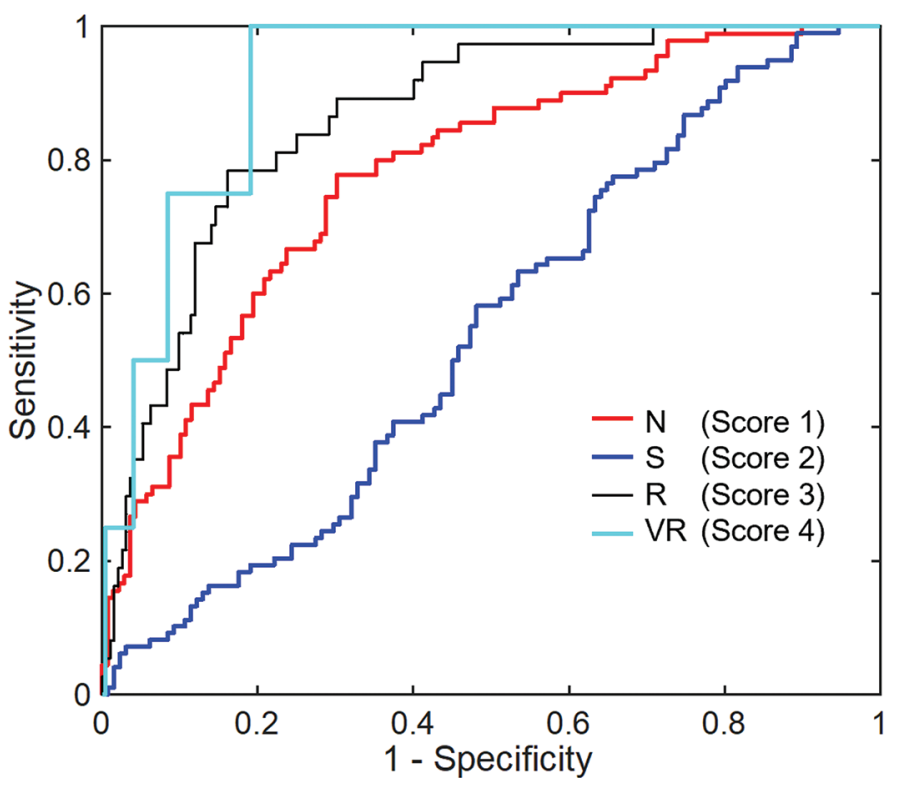

Figure 2. Receiver operator characteristic curves for deep learning classifier for 4 classifications of teat-end condition. Score $1(\mathrm{~N})=$ no callosity ring present; score $2(\mathrm{~S})=$ callosity ring present with no or only mild roughness and no keratin fronds; score $3(\mathrm{R})=$ callosity ring present with rough isolated fronds of old keratin extending 1 to $3 \mathrm{~mm}$ from the orifice; and score $4(\mathrm{VR})=$ callosity ring present with rough fronds of old keratin extending $\geq 4 \mathrm{~mm}$ from the orifice. 
Although data-balancing techniques were applied in this study, we anticipate further improvements with a larger training data set. As noted earlier, there is great potential in improving the quality of the digital images for deep learning.

During the deep learning process the subsampled (cropped) images of individual teats were resampled to $224 \times 224$ resolution, thus potentially reducing features that could have been used for deep learning. Future refinements in image acquisition are necessary to prevent missed observations due to image quality if the system is to be deployed to a field setting and optimize contrast and lighting of teat ends. Future refinements should include position and angle of camera, lighting, timing of shutter release, optimized focus on the teats, and determination of the optimal camera resolution. The optimal combination of these parameters is necessary to ensure that the majority of cattle in the herd are sampled if an automated system is deployed.

During data acquisition, the camera was manually held behind the cow, which resulted in variability in camera position between cattle. Having a camera in a fixed position would have been more realistic because mounting a camera in a fixed position will be neces-

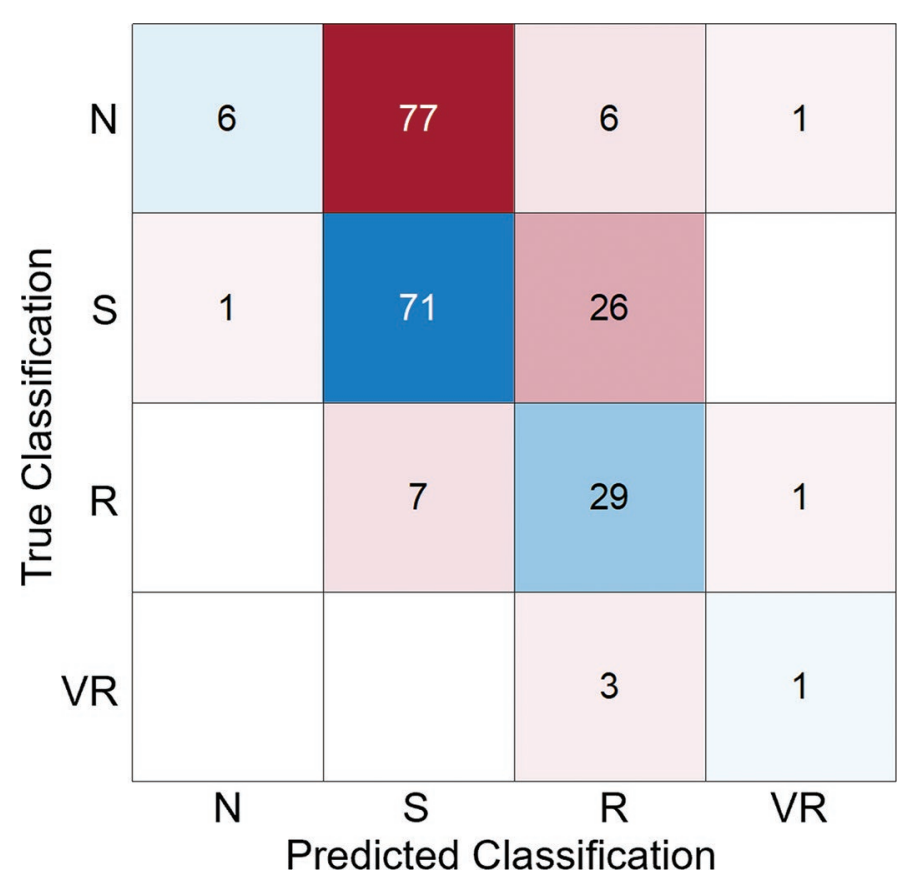

Figure 3. Confusion matrix for deep learning classifier for 4 classifications of teat-end condition. Score $1(\mathrm{~N})=$ no callosity ring present; score $2(\mathrm{~S})=$ callosity ring present with no or only mild roughness and no keratin fronds; score $3(\mathrm{R})=$ callosity ring present with rough isolated fronds of old keratin extending 1 to $3 \mathrm{~mm}$ from the orifice; and score $4(\mathrm{VR})=$ callosity ring present with rough fronds of old keratin extending $\geq 4 \mathrm{~mm}$ from the orifice. sary if a system is eventually developed for deployment on a commercial dairy. The effect of this variability in camera position on image quality may or may not be of importance in the development of the database for training a deep learning neural network. That is, if the camera position had been fixed, there would still have been variability due to position of the cow within the stall and due to variable height and shape of the udder. A heterogeneous data set, which has inconsistency in teat angle and position, should result in a more robust training data set, given the expected variability under field conditions. Similarly, some variation in lighting source and intensity within the training data set should result in the development of a more robust model as the lighting source and intensity will change between milking shifts (i.e., time of day) and between different milking facilities.

\section{Future Directions}

Opportunities with a deep learning teat-end classification system abound. Logistically, such a system could be most easily used in a rotary parlor, where a stationary camera could capture each individual cow from a single location in the parlor. Another site where this technology may have a profound effect is in robotic milking facilities where there is no practical or easy way to monitor teat-end condition due to difficulties in accessing the cow during the milking event (i.e., the physical challenge and danger of maneuvering around the robotic arm and the temporal challenge due to the time it takes to wait for cows to be milked). A future area of research will be the use of video capture technology. This may provide a more accurate assessment of teat-end condition compared with a static image as the average result of many images taken from an individual animal could be used to create the classification.

Another opportunity is linking the teat image data and its classification with the specific dairy cow data from other sources such as the herd (i.e., cow items and events) or the parlor management software programs. This could lead to both improvement of teat classification and a targeted approach to dairy cow health monitoring. For instance, we excluded cows with a nonlactating quarter in the current study. Our reasoning was that we wanted to reduce inadvertent variability from, for example, associated teat deformation or injuries. However, under practical conditions, cows with a nonlactating quarter should be included in the monitoring program because they can represent a significant proportion of the lactating herd (i.e., approximately 10\%; Bennedsgaard et al., 2010). In a fully automated system, connecting the cow data with the 


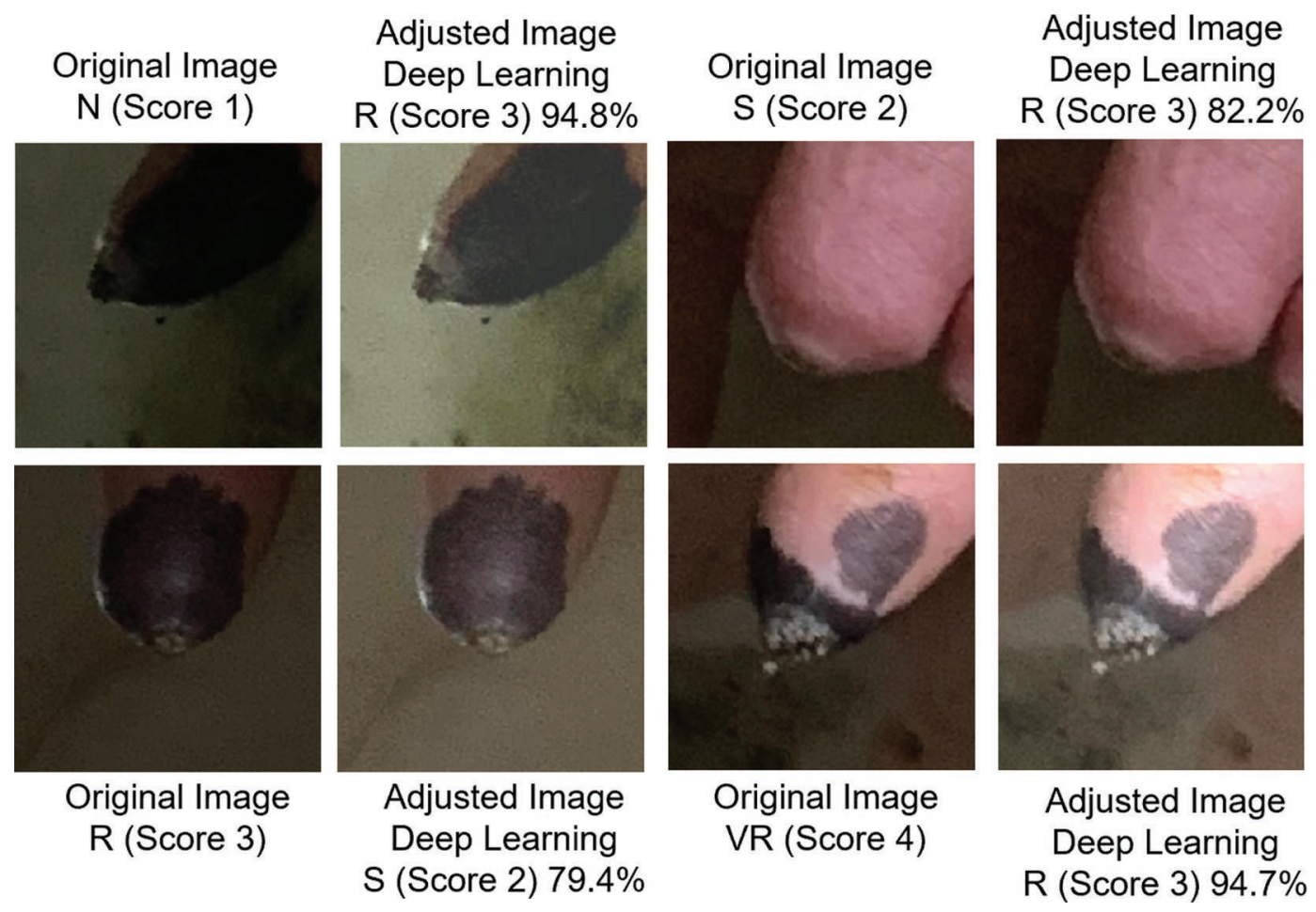

Figure 4. Teat images with and without contrast and brightness adjustments and their manual scores from the original image, along with the corresponding deep learning score predictions and percentages. Score $1(\mathrm{~N})=$ no callosity ring present; score $2(\mathrm{~S})=$ callosity ring present with no or only mild roughness and no keratin fronds; score $3(\mathrm{R})=$ callosity ring present with rough isolated fronds of old keratin extending 1 to $3 \mathrm{~mm}$ from the orifice; and score $4(\mathrm{VR})=$ callosity ring present with rough fronds of old keratin extending $\geq 4 \mathrm{~mm}$ from the orifice.

automated scoring system could facilitate exclusion of the nonlactating quarter from evaluation and thereby improve accuracy. Several research groups showed an association between milking characteristics and machine milking-induced changes in teat tissue condition (Nørstebø et al., 2018; Wieland et al., 2018). Linking cow- or quarter-level milk flow data from electronic on-farm milk meters could therefore further improve the accuracy of image-based classification of teat tissue condition.

Last, in the current study we focused on the evaluation of machine milking-induced long-term changes to the teat tissue. We believe that our work can be extended to assess short-term changes and teat skin condition using a similar approach.

\section{CONCLUSIONS}

We illustrated the feasibility of unsupervised deep learning to classify teat-end condition. Further refinements and automation of digital image acquisition and establishment of a larger database to improve the accuracy of the model have the potential to allow creation of an automated, on-farm, cow-side teat-end classification system.

\section{ACKNOWLEDGMENTS}

The authors thank the farm owners and their employees for their willingness to participate in the study and their support during the data collection. The authors have not stated any conflicts of interest.

\section{REFERENCES}

Aghamohammadi, M., D. Haine, D. P. Kelton, H. W. Barkema, H. Hogeveen, G. P. Keefe, and S. Dufour. 2018. Herd-level mastitisassociated costs on Canadian dairy farms. Front. Vet. Sci. 5:100. https://doi.org/10.3389/fvets.2018.00100.

Basran, P. S. 2020. Teat-end condition hyperkeratosis deep learning. Accessed Oct. 20, 2020. http://github.com/pbasran/TeatNet.

Basran, P. S., M. Wieland, and I. R. Porter. 2020. Technical note: A digital technique and platform for assessing dairy cow teat-end condition. J. Dairy Sci. 103:10703-10708. https://doi.org/10.3168/ jds.2020-18667.

Bennedsgaard, T. W., I. C. Klaas, and M. Vaarst. 2010. Reducing use of antimicrobials - Experiences from an intervention study in organic dairy herds in Denmark. Livest. Sci. 131:183-192. https:// doi.org/10.1016/j.livsci.2010.03.018.

Burmeister, J. E., L. K. Fox, D. D. Hancock, C. C. Gay, J. M. Gay, S. M. Parish, and J. W. Tyler. 1995. Survey of dairy managers in the Pacific Northwest identifying factors associated with teat chapping. J. Dairy Sci. 78:2073-2082. https://doi.org/10.3168/jds .S0022-0302(95)76833-3.

Chartrand, G., P. M. Cheng, E. Vorontsov, M. Drozdzal, S. Turcotte, C. F. Pal, S. Kadoury, and A. Tang. 2017. Deep learning: A primer 
for radiologists. Radiographics 37:2113-2131. https://doi.org/10 $.1148 / \mathrm{rg} .2017170077$.

Gleeson, D. 2013. Evaluation of hydrated lime as a cubicle bedding material on the microbial count on teat skin and new intramammary infection. Ir. J. Agric. Food Res. 52:159-171.

Gleeson, D. E., B. O'Brien, L. Boyle, and B. Earley. 2007. Effect of milking frequency and nutritional level on aspects of the health and welfare of dairy cows. Animal 1:125-132. https://doi.org/10 $.1017 /$ S1751731107658030.

Goldberg, J. J., P. A. Murdough, A. B. Howard, P. A. Drechsler, J. W. Pankey, G. A. Ledbetter, L. L. Day, and J. D. Day. 1994. Winter evaluation of a postmilking powdered teat dip. J. Dairy Sci. 77:748-758. https://doi.org/10.3168/jds.S0022-0302(94)77009-0.

Haeussermann, A., J. Britten, A. Britten, C. Pahl, N. Alveby, and E. Hartung. 2016. Effect of a multi-sided concave liner barrel design on thickness and roughness of teat-end hyperkeratosis. J. Dairy Res. 83:188-195. https://doi.org/10.1017/S0022029916000200.

Hamann, J., G. A. Mein, and S. Wetzel. 1993. Teat tissue reactions to milking: Effects of vacuum level. J. Dairy Sci. 76:1040-1046. https: //doi.org/10.3168/jds.S0022-0302(93)77432-9.

Hamann, J., B. Nipp, and K. Persson. 1994. Teat tissue reactions to milking: Changes in blood flow and thickness in the bovine teat. Milchwissenschaft 49:243-247.

Kenta. 2020. Oversampling for deep learning: Classification example. Accessed Sep. 4, 2020. https://www.mathworks.com/ matlabcentral/fileexchange/78020-oversampling-for-deep-learning -classification-example.

Liang, D., L. M. Arnold, C. J. Stowe, R. J. Harmon, and J. M. Bewley. 2017. Estimating US dairy clinical disease costs with a stochastic simulation model. J. Dairy Sci. 100:1472-1486. https://doi.org/10 .3168/jds.2016-11565.

Mein, G. A., F. Neijenhuis, W. F. Morgan, D. J. Reinemann, J. E. Hillerton, J. R. Baines, I. Ohnstad, M. D. Rasmussen, L. Timms, J. S. Britt, R. Fransworth, N. Cook, and T. Hemling. 2001. Evaluation of bovine teat condition in commercial dairy herds: 1 . Noninfectious factors. Pages 347-351 in Proc. 2nd Int. Symp. Mastit. Milk Qual. Natl. Mastit. Counc. Inc., Vancouver, BC, Canada.

Mikołajczyk, A., and M. Grochowski. 2018. Data augmentation for improving deep learning in image classification problem. Pages 117-122 in 2018 International Interdisciplinary PhD Workshop (IIPhDW). IEEE, Swinoujście, Poland.

Neijenhuis, F., H. W. Barkema, H. Hogeveen, and J. P. Noordhuizen. 2000. Classification and longitudinal examination of callused teat ends in dairy cows. J. Dairy Sci. 83:2795-2804. https://doi.org/10 3168/jds.S0022-0302(00)75177-0.
Neijenhuis, F., H. W. Barkema, H. Hogeveen, and J. P. Noordhuizen. 2001. Relationship between teat-end callosity and occurrence of clinical mastitis. J. Dairy Sci. 84:2664-2672. https://doi.org/10 .3168/jds.S0022-0302(01)74720-0.

Nørstebø, H., A. Rachah, G. Dalen, O. Rønningen, A. C. Whist, and O. Reksen. 2018. Milk-flow data collected routinely in an automatic milking system: An alternative to milking-time testing in the management of teat-end condition? Acta Vet. Scand. 60:2. https://doi.org/10.1186/s13028-018-0356-x.

O'Shea, J. 1987. Machine milking and mastitis. Section 2: Machine milking factors affecting mastitis. A literature review. Bull. Int. Dairy Fed. 215:5-32.

Oliver, S. P. S. E. Murinda, and B. M. Jayarao. 2011. Impact of antibiotic use in adult dairy cows on antimicrobial resistance of veterinary and human pathogens: A comprehensive review. Foodborne Pathog. Dis. 8:337-355. https://doi.org/10.1089/fpd.2010.0730.

Rasmussen, M. D. 1993. Influence of switch level of automatic cluster removers on milking performance and udder health. J. Dairy Res. 60:287-297. https://doi.org/10.1017/s0022029900027631.

Rawat, W., and Z. Wang. 2017. Deep convolutional neural networks for image classification: A comprehensive review. Neural Comput. 29:2352-2449. https://doi.org/10.1162/neco_a_00990.

Ruegg, P. L. 2017. A 100-year review: Mastitis detection, management, and prevention. J. Dairy Sci. 100:10381-10397. https://doi .org/10.3168/jds.2017-13023.

Wieland, M., D. V. Nydam, N. Älveby, P. Wood, and P. D. Virkler. 2018. Short communication: Teat-end shape and udder-level milking characteristics and their associations with machine milkinginduced changes in teat tissue condition. J. Dairy Sci. 101:1144711454. https://doi.org/10.3168/jds.2018-15057.

Wieland, M., P. D. Virkler, A. Weld, J. M. Melvin, M. R. Wettstein, M. F. Oswald, C. M. Geary, R. D. Watters, R. Lynch, and D. V. Nydam. 2020. The effect of 2 different premilking stimulation regimens, with and without manual forestripping, on teat tissue condition and milking performance in Holstein dairy cows milked 3 times daily. J. Dairy Sci. 103:9548-9560. https://doi.org/10.3168/ jds.2020-18551.

\section{ORCIDS}

I. R. Porter (® https://orcid.org/0000-0002-5501-4683

M. Wieland ๑ https://orcid.org/0000-0003-0513-1782

P. S. Basran ๑ https://orcid.org/0000-0002-1573-1549 